\title{
Attitude, Practice and its Associated Factors towards Diabetes Complications among Type 2 Diabetic Patients at Addis Zemen District Hospital, Northwest Ethiopia
}

yitayeh belsti ( $\square$ yitayehbelsti@gmail.com )

University of Gondar College of Medicine and Health Sciences https://orcid.org/0000-0001-8984-1495

\section{Yonas Akalu}

University of Gondar College of Medicine and Health Sciences

\section{Yaregal Animut}

University of Gondar College of Medicine and Health Sciences

\section{Research article}

Keywords: Attitudes, Practice, Diabetes Mellitus, Complications, associated factors, Ethiopia

Posted Date: February 25th, 2020

DOI: https://doi.org/10.21203/rs.2.16307/v2

License: (a) (i) This work is licensed under a Creative Commons Attribution 4.0 International License. Read Full License

Version of Record: A version of this preprint was published at BMC Public Health on May 26th, 2020. See the published version at https://doi.org/10.1186/s12889-020-08953-6. 


\section{Abstract}

Background The aim of this study was to assess the level of attitude, practices, and its associated factors towards complications of diabetes mellitus among type 2 diabetes patients. Methods A cross-sectional study was conducted among Type 2 diabetes patients visiting the diabetes clinic at Adiss Zemen District Hospital in Northwest Ethiopia. Interviewer administered structured questionnaire was used to collect data from 402 patients. Multivariable logistic regression was used to determine factors associated with attitudes and practices towards diabetes complications. AOR with $95 \% \mathrm{Cl}$ and p-value less than 0.05 was considered to identify significant associated factors. Results Two third of the study participants $65.2 \%(95 \% \mathrm{Cl}: 60.2,69.4)$ had a good attitude level while less than half of study participants $48.8 \%(95 \% \mathrm{Cl}: 44.0,53.5)$ had a good practice on diabetes complications. Educational status of: read and write ( $\mathrm{AOR}=2.32,95 \% \mathrm{Cl}=1.264 .27)$, primary school $(\mathrm{AOR}=4.31,95 \% \mathrm{Cl}=2.06,9.02)$, high school and above $(\mathrm{AOR}=2.79,95 \% \mathrm{Cl}=1.41,5.50)$, and urban residence $(A O R=1.80,95 \% \mathrm{Cl}=1.12$ 2.91) were significant factors for good attitude while educational status of: read and write ( $A O R=1.96,95 \% \mathrm{Cl}=1.06,3.61)$, high school and above $(\mathrm{AOR}=2.57,95 \% \mathrm{Cl}=1.32,5.02)$ were associated with diabetes complication practices. Conclusions Greater proportion of diabetes patients had relatively good attitude but poor practice towards diabetes complication prevention. Residence was significant contributing factor for good attitude whereas educational status was significantly associated with both attitude and practice. The current study suggests the need of structured educational programs about diabetes complications on a regular basis to improve patient's attitude and practice.

\section{Introduction}

Diabetes Mellitus(DM) is a serious, chronic disease that occurs either by impaired insulin secretion or insulin resistance or both(1). DM is one of the four priority non-communicable diseases (NCDs) targeted for prevention and control by World Health Organization 2011(2). It was estimated that in 2019 there were 500 million people with diabetes worldwide (3) and predicted to be 693 million by 2045(4).Type 2 diabetes will be the predominant public health problem in Africa which is expected to be 28 million by 2030(5) and 41.6 million in 2045(6). There were 2, 652,129 cases of diabetes in Ethiopia in 2017 making it the first among the top five countries of Africa for several people with diabetes with an age of 18-99 years(6). Studies in various parts of Ethiopia also showed that the prevalence of diabetes varies from $0.3 \%$ to $7.0 \%(2)$.

Diabetes is identified as the main cause of premature death and disability $(2,6,7)$. Most of death and disability is caused by diabetic complications that damage the heart, blood vessels, eyes, kidneys, and nerves $(8,9)$. Such damage increases the chance of foot ulcers, infection, and the eventual need for limb amputation(10). Diabetic retinopathy, one of main diabetic complication, is an important cause of blindness. Diabetes is also among the leading causes of kidney failure(7). According to the WHO report in 2016, DM is attributed to $2 \%$ death among all causes of death in Ethiopia, which is mainly attributed by its complications(7). Studies conducted on prevalence of acute and chronic complication in different parts of Ethiopia showed that the prevalence for: retinopathy $5.0 \%$ to $43.4 \%$, neuropathy $6.0 \%$ to $41.0 \%$, foot ulcer $1.7 \%$ to $17 \%$, nephropathy $1-20 \%$, hypertension $3 \%$ to $39 \%$, and erectile dysfunction $1 \%$ to $22 \%(11)$.

The international diabetic Federation (IDF) estimated that the total health expenditure due to diabetes was $\$ 3.3$ billion worldwide in 2017. Most countries spend between $5 \%$ and $20 \%$ of their total health costs on diabetes 
mainly to prevent and treat diabetic complications(6). All major complications of diabetes are preventable by good control of blood glucose levels, blood pressure, and cholesterol levels. This requires a high level of education of the person with diabetes in managing their condition, and access to insulin, oral medications, and monitoring equipment(12).

There is increasing amount of evidence that patient education is the most effective way to lessen the complications of diabetes and its management by improving their attitude and practice(13). Adverse attitudes and psychological problems such as depression are common among diabetes patients and can lead to poor diabetes management leading to diabetic complication $(14,15)$. There is strong evidence that individual who are educated and diligent with their diabetes self-care achieve better and durable diabetic control $(16,17)$.

Furthermore, previous studies on knowledge, attitude and Practice on diabetes have supported the needs of greater awareness of prevention, diagnosis, and risk factor Control in diabetes(18). Good attitude towards DM complication helps motivate patients to change any harmful dietary and lifestyle habits(19).

Though there are few literatures on the prevalence of diabetic complications, there is no published data on attitude and practices towards complications of diabetic among type 2 diabetic patients in Ethiopia. Thus, this study was conducted to assess the attitude and practices and its associated factor of diabetic complication among patients who attend Adiss Zemen Hospital, Northwest Ethiopia. The information generated from this study will provide important input for its prevention strategies, which in turn help to improve quality of care for type 2 type 2 diabetic patients and to reduce the burden associated with diabetes complications.

\section{Methodology}

\section{Study setting, design, and Period}

Institution based cross-sectional study was conducted from April 02, 2019 to June 02, 2019 at Addis Zemen District Hospital, South Gondar, Northwest Ethiopia. Addis Zemen District Hospital is found in Addis Zemen town which is an administrative town of Libo Kemkem District, South Gondar Zone, Amhara regional state. It is located 90 kilometers far from Bahir Dar (the capital city of Amhara Regional State) and 656 kilometers from Addis Ababa in the north direction

\section{Study population and eligibility criteria}

Type 2 diabetic patients who came to diabetic clinic during the data collection period were included except those who were in a severe illness that limits them to respond for questionnaires and those who were health professionals.

\section{Sample size determination and sampling technique}

The sample size was calculated using a single population proportion formula considering $p=50 \%$ (magnitude of good practice towards DM complications), $95 \%$ level of confidence, and $5 \%$ margin of error. Then sample size became 384. After adding a $5 \%$ non-response rate, the sample size becomes 404 . Systematic random sampling techniques were employed to select the study participants.

\section{Data collection instrument and procedure}


A structured pretested interviewer-administered questionnaire was used to collect data regarding to attitude, practice and associated factors. The questionnaire contained 9 attitude and 13 practice related questions towards diabetes complications adapted from literatures(20-23). It also includes important socio-demographic variables like: age, sex, residence, marital status, occupation, educational status, income, family history of DM, and duration since diagnosis as diabetic. The questionnaire was prepared in English and translated to Amharic and then translated back to English by a language expert to check its consistency and wording. Five Bachelor degree holder nurses were recruited for the data collection. In socio-demographic variables educational level was categorized as follows; cannot read and write, primary school and can read and write, informal education and can read and write, secondary school and above. Main aim here was to identify weather they can read and write, not to miss the positive effect of reading and writing on their attitude and practice. If the study participant went to primary school but couldn't read and write obviously they will be put under unable to read and write. In Ethiopia, there are people who attend informal education and religious education but did not attend primary school and able to read and write, for such candidates we group them in able read and write. Settling in country side outside of big cities or towns in Ethiopia is referred as rural residents(24).

\section{Assessment of Attitude}

We have used 9 questions adapted from different similar studies and literatures $(25,26)$ to assess the attitude of the patients each question had a three choices of responses (agree, neither agree nor disagree, and disagree). A score of " 1 " was given for favorable attitude (correct answer) and " 0 " for unfavorable attitude (incorrect answer) of each respective attitude questions(20). All possible correct answers were summated out of 9. Accordingly, the attitude of the patient was calculated by summating the correct answers and calculating the mean value as 5 with maximum possible correct answers and 9 . The participant who mentioned less than mean (5) correct answers rated as poor attitudes. The participant who mentioned $\geq 5$ correct answers rated as good attitude.

Attitude questions and their respective response score

1. Do you think you can lead a normal life if you take appropriate measures for diabetes? Agree "1" neither agree and disagree and disagree " 0 "

2. Regular exercise prevents further complication? Agree "1", neither agree and disagree and disagree" 0 "

3. Glycemic control has no role in preventing diabetic complications? Disagree "1", while agree and neither agree and disagree given score of " 0 "

4. My diabetic diet spoils my social life? Agree and neither agree and dis agree scored as " 0 " but disagree scored as "7"

5. Do you believe that you could prevent diabetic complications? Agree "1" neither agree and disagree" 0 "

6. Do you agree that dietary modification is important to prevent diabetic complication? Agree "1" neither agree and disagree" 0 "

7. Do you agree Weight reduction is important to prevent diabetic complication? Agree "1" neither agree and disagree" 0 "

8. I avoid telling people I have diabetics? Agree and neither agree and dis agree scored as "O" but disagree scored as " 7 " 
9. Diabetic is the worst thing that has ever happened to me? Agree and neither agree and dis agree scored as "O" but disagree scored as " 7 "

\section{Assessment of Practice}

There were 13 questions which assess the practice of the patients about diabetic complications, 10 questions had a "Yes", or "No" response, "Yes" indicates a practice of recommended activity. A score "1" was given for "Yes", and "0" for "No". The remaining three measures of practice questions scored as follows: How often have you done physical work or exercise in the last week? Those who respond "Never" was given a score of "0" but the remaining recommended options (daily, almost daily, 2-3 times per day and once a week) were given a score of " 1 ". For question "How often do you drink alcohol?" the response never was scored as " 1 " which is recommended response for diabetic patients while the remaining responses (rarely, nearly every day, 2-3 times/ day, and weekly) given a score of " 0 ". Finally since the recommended type water for foot care is warm water but not too hot or too cold for the question "What type of water do you use to wash your feet? " warm but not hot water was recorded as " 1 " and cold water recorded as " 0 ".

Accordingly the practice of the patients calculated as a summation of their answers with the maximum possible score of 13 and patients whose mean practice level was $\geq 8$ diabetic complication prevention activities were labeled as having good practice whereas those who practiced less than 8 were categorized poor level of practice $(20,27,28)$.

\section{Practice Questionnaires}

1. Do you ever forget to take your medicine/ insulin?

2. Are you careless at times about taking your medicine?

3. When you feel better do you sometimes stop taking your medicine?

4. Sometimes if you feel worse when you take the medicine, do you stop taking it?

5. How often have you done physical work or exercise in the last week?

6. Do you modify your diet according to the recommendations of your physician?

7. How often do you drink alcohol?

8. Do you smoke cigarette?

9. Will you wear footwear as recommended by your health worker when you go to exercise?

10. What type of water do you use to wash your feet?

11. Do you take care when you cut your toe nails?

12. Do you conduct periodic kidney examination?

13. Do you take regular checkup of eye by eye specialist?

\section{Data quality management/control}

One day training was given for data collectors and supervisors about the data collection procedure and ethical issues. Pretest was conducted on 60 type 2 DM patients at the University of Gondar specialized Hospital DM clinic. There data collection was closely supervised by two health officer supervisors and investigators. The 
collected data were checked for its completeness in a daily meeting. Data clean up and crosschecking was done before analysis.

\section{Data processing and analysis}

The data were checked for completeness and entered to Epi Info version 7 and were exported to SPSS Version 20 software. Descriptive statistics such as frequencies and percentage were used. Bivariate analysis was carried out for all independent variables with an outcome variable and variables with P-value $\leq 0.2$ were entered in to multivariable logistic regression model to identify the independent associated factors of attitude and practice. Adjusted odds ratio with $95 \% \mathrm{Cl}$ and p-value less than 0.05 was considered to declare significant associated factors.

\section{Results}

\section{Socio demographic characteristics}

A total of 404 patients were included in the study of which 402 responded, yielding a response rate of $99.5 \%$. Of the total participants, 225 (56\%) were females and 243 (60.4\%) were urban dwellers. Most of the respondents, 150 (37.3\%) were aged 45-70 years. The majority 304 (75.6\%) of the participants were orthodox Christians and 348 (86.6\%) were from Amhara ethnic group. One hundred and eighteen (29.4\%) study participants had a family history of diabetic mellitus. Out of the total respondents, 242 (61.3\%) were married, $110(27.4 \%)$ are unable to read and write, were urban dwellers, 85 (21\%) were farmers, and $156(38.8 \%)$ had a monthly income below 500 Ethiopian birr (Table 1).

Table 1: Socio demographic characteristics of Type 2 adult DM patients at Adiss Zemen District Hospital, Gondar, Ethiopia, 2019(N=402)

Abbreviations: $E T B=$ Ethiopian Birr, DM= Diabetes mellitus, $N G O=$ Non-governmental organizations

\section{Attitude of type 2 diabetic patients towards complications of diabetes}

Two-thirds of the study participants $65.2 \%(95 \% \mathrm{Cl}: 60.2,69.4)$ possessed good attitude levels. Most $(74.1 \%)$ of the respondents agreed that diabetic complications could be prevented. Nearly three quarters (74.1\%) of respondents thought they could lead a normal life if they take appropriate measures for diabetes. Over two-third of the participants $69(16.9 \%)$ believed that diabetic complications can be prevented by having good glycemic control. The majority (79.9\%) of participants agreed that regular exercise can prevent complications of diabetes. Dietary modification and weight reduction was considered important to prevent diabetic complications by $91.8 \%(n=369)$ and $46.3 \%(n=186)$ respondents, respectively. One hundred thirty-five (33.6\%) respondents believed that their diabetic diet spoils their social life. Furthermore, 214(53.2\%) respondents thought diabetics were the worst thing that ever happened to them (Table 2).

Table 2: Frequency distribution of participant's response on attitude related questions on DM complications among Type 2 adult DM patients at Adiss Zemen District Hospital, Gondar, Ethiopia, April, 2019(N=402) 


\begin{tabular}{|c|c|c|c|c|c|}
\hline Variables & Frequency & Percent (\%) & Variables & Frequencies & $\%$ \\
\hline Sex & & & \multirow{2}{*}{\multicolumn{3}{|c|}{$\begin{array}{l}\text { I can lead a normal life if I take } \\
\text { appropriate measures for diabetes }\end{array}$}} \\
\hline Male & 177 & 44.0 & & & \\
\hline Female & 225 & 56.0 & Agree & 298 & 74.1 \\
\hline Age & & & Disagree & 64 & 15.9 \\
\hline $18-30$ & 134 & 33.3 & Neither nor & 70 & 10 \\
\hline $31-45$ & 118 & 29.4 & disagree & & \\
\hline $45-70$ & 150 & 37.3 & \multirow{2}{*}{\multicolumn{3}{|c|}{$\begin{array}{l}\text { Regular exercise prevents further } \\
\text { complication }\end{array}$}} \\
\hline Level of Education & & & & & \\
\hline Cannot read and write & 110 & 27.4 & Agree & 321 & 79.9 \\
\hline Informal education can read and write & 124 & 30.8 & Disagree & 25 & 6.2 \\
\hline Primary school and can read and write & 77 & 19.2 & Neither nor & 56 & 13.9 \\
\hline Secondary school and above & 91 & 22.6 & & & \\
\hline Marital status & & & \multirow{2}{*}{\multicolumn{3}{|c|}{$\begin{array}{l}\text { Glycemic control has no role in } \\
\text { preventing complications }\end{array}$}} \\
\hline Married & 202 & 50.2 & & & \\
\hline Divorced & 37 & 9.2 & Agree & 68 & 16.9 \\
\hline Widowed & 49 & 12.2 & Disagree & 333 & 82.8 \\
\hline Single & 114 & 28.4 & Neither nor & 1 & 2 \\
\hline Occupation & & & disagree & & \\
\hline Farmer & 85 & 21.1 & \multicolumn{3}{|c|}{ Diabetic spoils my social life } \\
\hline Government worker & 46 & 11.4 & Agree & 135 & 33.6 \\
\hline Merchant & 104 & 25.9 & Disagree & 232 & 57.7 \\
\hline Housewife & 77 & 19.2 & Neither nor & 35 & 8.7 \\
\hline NGO worker & 90 & 22.4 & disagree & & \\
\hline Religion & & & \multicolumn{3}{|c|}{ I could prevent diabetic complications } \\
\hline Orthodox & 304 & 75.6 & Agree & 298 & 74.1 \\
\hline Muslim & 68 & 16.9 & Disagree & 40 & 10 \\
\hline Protestant & 30 & 7.5 & Neither nor & 64 & 15.9 \\
\hline Ethnicity & & & disagree & & \\
\hline Amhara & 348 & 86.6 & \multirow{2}{*}{\multicolumn{3}{|c|}{$\begin{array}{l}\text { Dietary modification is important to } \\
\text { prevent diabetic complication }\end{array}$}} \\
\hline Kimant & 35 & 8.7 & & & \\
\hline Tigrie & 19 & 4.7 & Agree & 369 & 91.8 \\
\hline Residence & & & Disagree & 29 & 7.2 \\
\hline Rural & 159 & 39.6 & Neither nor & 4 & 1 \\
\hline Urban & 243 & 60.4 & disagree & & \\
\hline Duration of DM & & & \multirow{2}{*}{\multicolumn{3}{|c|}{$\begin{array}{l}\text { Weight reduction is important to prevent } \\
\text { diabetic complication }\end{array}$}} \\
\hline$(1-5)$ & 270 & 67.2 & & & \\
\hline$(6-10)$ & 93 & 23.1 & Agree & 186 & 46.3 \\
\hline$>10$ & 39 & 9.7 & Disagree & 104 & 25.9 \\
\hline Type of medication they use & & & Neither nor & 112 & 27.9 \\
\hline Oral & 133 & 33.1 & disagree & & \\
\hline Injectable & 218 & 54.2 & \multicolumn{3}{|c|}{ I don't tell people as I have diabetics } \\
\hline Both & 51 & 12.7 & Agree & 38 & 9.5 \\
\hline Family history of DM & & & Disagree & 349 & 86.8 \\
\hline Yes & 118 & 29.4 & Neither nor & 15 & 3.7 \\
\hline No & 284 & 70.6 & disagree & & \\
\hline Income( ETB) & & & \multirow{2}{*}{\multicolumn{3}{|c|}{$\begin{array}{l}\text { Diabetes is the worst thing that have ever } \\
\text { happened to me }\end{array}$}} \\
\hline$<500$ & 156 & 38.8 & & & \\
\hline $500-1500$ & 68 & 16.9 & Agree & 214 & 53.2 \\
\hline $1501-2500$ & 86 & 21.4 & Disagree & 173 & 43 \\
\hline \multirow[t]{4}{*}{$>2500$} & 92 & 22.9 & Neither nor & 15 & 3.7 \\
\hline & & & \multicolumn{3}{|l|}{ Total attitude level } \\
\hline & & & Good attitude & 262 & 65.2 \\
\hline & & & Poor attitude & 140 & 34.8 \\
\hline
\end{tabular}




\section{Factors associated with attitude towards complications of diabetes}

The residence and educational status of the respondents had a significant influence on attitude. Subjects who informal school and can read and write were 2.3 times ( $\mathrm{AOR}=2.32,95 \% \mathrm{Cl}=1.26,4.27$ ) more likely to have good attitude as compared to those who cannot read and write. Type 2 diabetic patients who attained primary school and can read and write were 4 times ( $\mathrm{AOR}=4.31,95 \% \mathrm{Cl}=2.06,9.02)$ more likely to have good attitude than those who cannot read and write. Similarly, those who conquered secondary school and above were 2.8 times $(A O R=2.79,95 \% \mathrm{Cl}=1.41,5.50)$ more likely to have good attitude than those who cannot read and write. Patients from urban area were 1.8 times $(A O R=1.80,95 \% \mathrm{Cl}=1.12,2.91)$ more likely to have a good attitude than those who live in a rural area (Table 3).

Table 3: Factors affecting good attitude towards DM complication among Type 2 adult DM patients at Adiss Zemen Hospital, Gondar, Ethiopia, April 2019.

*significant at P-value $\leq 0.05, * *$ significant at P-value $\leq 0.01$

Abbreviations: ETB=Ethiopian Birr, $D M=$ Diabetes mellitus, $N G O=$ Non-governmental organizations, COR=Crude Odds Ratio, AOR=Adjusted Odds Ratio

\section{Practice of type 2 diabetic patients towards complications of diabetes}

Almost half of the respondents $48.8 \%$ (95\% Cl: 44.0, 53.5) had good practice towards diabetic complications. More than two-third of the patients $280(69.7 \%)$ reported that they never forgot to take their medication. One hundred nine (27.1\%) and $179(44.5 \%)$ respondents said that they stopped their medication when they felt better and felt worse, respectively. Only about $21(5 \%)$ respondents performed exercise daily. The majority (86.6\%) of them change their diet according to the recommendations of their physician. Most (80.1\%) of respondents monitor their blood glucose level in hospital. One hundred fifty-one (37.6\%) of respondents monitor their blood glucose level monthly. Greater than 239 (59\%) of respondents reported daily feet examination. Only $48(11.9 \%)$ of respondents use hot water to wash their foot and $45.5 \%$ take care when they cut their nail. Regular kidney and eye checkup was practiced by $29.9 \%$ and $7.7 \%$ of study participants, respectively. Nearly all, $96.8 \%$ of respondents do not smoke and $188(46.8 \%)$ of the participants never drink alcohol (Table 4).

Table 4: Response distribution of practice on DM complications related questions among Type 2 adult DM patients at Adiss Zemen District Hospital, Gondar, Ethiopia, April, 2019 


\begin{tabular}{|c|c|c|c|c|}
\hline \multirow[t]{2}{*}{ Variables } & \multicolumn{2}{|c|}{ Attitude status } & \multirow[t]{2}{*}{ COR(95\%CI) } & \multirow[t]{2}{*}{ AOR(95\%CI) } \\
\hline & $\begin{array}{l}\text { Good } \\
\text { attitude }\end{array}$ & Poor attitude & & \\
\hline \multicolumn{5}{|l|}{ Level of Education } \\
\hline Can't read and write & 49 & 61 & 1 & \\
\hline $\begin{array}{l}\text { Informal school and Can read and } \\
\text { write }\end{array}$ & 88 & 36 & $3.04(1.77,5.22)^{* *}$ & $2.32(1.26,4.27)^{* *}$ \\
\hline Primary school and can read and write & 60 & 17 & $4.39(2.28,8.47)^{* *}$ & $4.31(2.06,9.02)^{* *}$ \\
\hline Secondary school and above & 65 & 26 & $3.11(1.73,5.62)^{* *}$ & $2.79(1.41,5.50)^{* *}$ \\
\hline \multicolumn{5}{|l|}{ Marital status } \\
\hline Married & 144 & 58 & 1 & 1 \\
\hline Divorced & 25 & 12 & $0.84(0.40,1.78)$ & $0.96(0.41,2.22)$ \\
\hline Widowed & 22 & 27 & $0.33(0.17,0.62) *$ & $0.51(0.24,1.08)$ \\
\hline Single & 71 & 43 & $0.67(0.41,1.08)$ & $0.41(0.22,1.72)$ \\
\hline \multicolumn{5}{|l|}{ Occupation } \\
\hline Farmer & 48 & 36 & 1 & 1 \\
\hline Government employee & 29 & 17 & $1.25(0.60,2.62)$ & $1.33(0.58,3.04)$ \\
\hline Merchant & 72 & 32 & $1.65(0.91,3.01)$ & $1.56(0.79,3.06)$ \\
\hline House wife & 56 & 21 & $1.96(1.01,3.79) *$ & $2.18(0.95,4.49)$ \\
\hline NGO worker & 56 & 34 & $1.21(0.66,2.22)$ & $1.12(0.57,2.19)$ \\
\hline \multicolumn{5}{|l|}{ Residence } \\
\hline Rural & 87 & 72 & 1 & \\
\hline Urban & 175 & 68 & & \\
\hline Duration of DM & & & $2.13(1.40,3.24)^{* *}$ & $1.80(1.12,2.91)^{* *}$ \\
\hline $1-5$ & 186 & 84 & 1 & \\
\hline $6-10$ & 56 & 37 & $0.68(0.41,1.11)$ & $0.79(0.46,1.38)$ \\
\hline$>=10$ & 20 & 19 & $0.47(0.24,0.93)^{*}$ & $0.55(0.25,1.25)$ \\
\hline \multicolumn{5}{|l|}{ Income(ETB) } \\
\hline$<500$ & 110 & 46 & 1 & 1 \\
\hline $500-1500$ & 36 & 32 & $0.47(0.26,0.85)^{*}$ & $0.55(0.28,1.08)$ \\
\hline $1501-2500$ & 50 & 36 & $0.58(0.34,1.01)^{*}$ & $0.52(0.27,1.99)$ \\
\hline$>2500$ & 66 & 26 & $1.06(0.60,1.88)$ & $0.69(0.35,1.37)$ \\
\hline
\end{tabular}




\begin{tabular}{lcc}
\hline Variables & Frequencies & $\%$ \\
\hline Forget to take medicine/ insulin & 122 & 30.3 \\
$\quad$ Yes & 280 & 69.7 \\
$\quad$ No & 114 & 28.4 \\
Careless at times about taking medicine & 288 & 71.6 \\
$\quad$ Yes & & \\
$\quad$ No & 109 & 27.1 \\
Stop taking medicine when feel better & 293 & 72.9 \\
$\quad$ Yes & 179 & 44.5 \\
No & 223 & 55.5 \\
Stop taking medicine when feel worse & & \\
Yes & 186 & 46.3 \\
No & 43 & 10.7 \\
Physical work or exercise in the last week & & 24.6 \\
Never & 99 & 13.2 \\
Once a week & 53 & 5.2 \\
2-3 times per week & 21 & 14.2 \\
Almost daily & & 18.4 \\
Daily & 57 & 9.0 \\
Duration of physical work or exercise & 74 & 12.2 \\
<10Minutes/day & 36 & \\
10-20Minutes/day & 49 & \\
20-30Minutes/day & & \\
>30Minutes/day & & \\
Diet & &
\end{tabular}

Diet modification according to the recommendations of physician

$\begin{array}{lll}\text { Yes } & 348 & 86.6 \\ \text { No } & 54 & 13.4\end{array}$

Monitoring blood glucose

Self- monitoring

68

16.9

Local pharmacy

12

3.0

Hospital

322

80.1

Barriers for self-blood glucose monitoring

Too expensive

$128 \quad 31.8$

Too painful

6

1.5

Don't know how to test

77

19.2

Other

123

30.6

Frequency of blood glucose monitoring Monthly

$151 \quad 37.6$

Every 2 month

165

41.0

Every 3 month

86

21.4

checking feet

Never

41

10.2

Daily

239

59.5

Once a week

Rarely

116

28.9

Drinking alcohol

Never

188

46.8

Weekly 
Nearly every day $\quad 29 \quad 7.2$

Rarely

101

25.1

Cigarette smoking

Yes

13

3.2

No

389

96.8

Wearing footwear during exercise as recommended by health professionals

Yes

196

48.8

No

206

51.2

Type of water used to wash feet

Cold water

354

88.1

Warm water but not hot

48

11.9

care during cutting toe nails

Yes

183

45.5

No

219

54.5

Periodic kidney examination

Yes

120

29.9

No

282

70.1

Regular checkup of eye by eye specialist

Yes

31

7.7

No

371

92.3

Practice level

Good practice

196

48.8

Poor practice

206

51.2

Abbreviations: $\mathrm{DM}=$ Diabetic mellitus

\section{Factors associated with practice towards complications of diabetes}

Educational status was the single independent factor associated with patients practice towards diabetic complications. The odds of good practice towards prevention of complications of diabetes were two times $(A O R=1.96,95 \% \mathrm{Cl}=1.06,3.61)$ more likely among type 2 diabetic patients who were informal school and can read and write, four times $(\mathrm{AOR}=4.31,95 \% \mathrm{Cl}=2.06,9.02)$, more likely among participants attains primary school and can read and write and two point six times (AOR=2.57, 95\% $\mathrm{Cl}=1.32,5.02)$ more likely among who attains secondary school and above than those who cannot read and write (Table 5).

Table 5: Factors affecting good practice towards DM complication among Type 2 adult DM patients at Adiss Zemen Hospital, Gondar, Ethiopia, April, 2019.

*significant at P-value $\leq 0.05, * *$ significant at P-value $\leq 0.01$

Abbreviations: $D M=$ Diabetes mellitus, $N G O=$ Non-governmental organizations, COR= Crude Odds Ratio, AOR= Adjusted Odds Ratio

\section{Discussion}




\begin{tabular}{|c|c|c|c|c|}
\hline \multirow[b]{2}{*}{ Variables } & \multicolumn{2}{|c|}{ Practice level } & \multirow[t]{2}{*}{ COR(95\%CI) } & \multirow[t]{2}{*}{ AOR(95\%CI) } \\
\hline & $\begin{array}{l}\text { Good } \\
\text { practice }\end{array}$ & $\begin{array}{l}\text { Poor } \\
\text { practice }\end{array}$ & & \\
\hline Age & $\mathrm{N}$ & & & \\
\hline $18-30$ & 81 & 53 & 1 & 1 \\
\hline $31-45$ & 53 & 65 & $0.53(0.32,0.88) *$ & $0.69(0.35,1.40)$ \\
\hline$>=45$ & 62 & 88 & $0.46(0.29,0.74)^{*}$ & $0.59(0.30,1.15)$ \\
\hline \multicolumn{5}{|l|}{ Level of education } \\
\hline Can't write and read & 33 & 77 & 1 & 1 \\
\hline $\begin{array}{l}\text { Informal school and can Read and } \\
\text { write }\end{array}$ & 67 & 57 & $\begin{array}{l}2.74(1.60 \\
4.70)^{* *}\end{array}$ & $1.96(1.06,3.61) *$ \\
\hline $\begin{array}{l}\text { Primary school and can read and } \\
\text { write }\end{array}$ & 38 & 39 & $2.27(1.24,4.16)^{*}$ & $1.53(0.78,3.01)$ \\
\hline Secondary school and above & 58 & 33 & $4.10(2.27,7.40)^{* *}$ & $\begin{array}{l}2.57(1.32 \\
5.02)^{* *}\end{array}$ \\
\hline \multicolumn{5}{|l|}{ Marital status } \\
\hline Married & 94 & 108 & 1 & \\
\hline Divorced & 18 & 19 & $1.09(0.54,2.20)$ & $1.13(0.51,2.52)$ \\
\hline Widowed & 16 & 33 & $0.56(0.29,1.08)$ & $0.99(0.46,2.12)$ \\
\hline Single & 68 & 46 & $1.70(1.07,2.71)$ & $1.11(0.58,2.13)$ \\
\hline \multicolumn{5}{|l|}{ Occupation } \\
\hline Farmer & 38 & 47 & 1 & \\
\hline Government employee & 12 & 34 & $0.44(0.20, .96)$ & $0.39(0.17,1.90)$ \\
\hline Merchant & 59 & 45 & $1.62(0.91,2.89)$ & $1.49(0.79,2.82)$ \\
\hline House wife & 37 & 40 & $1.14(0.62,2.12)$ & $1.33(0.68,2.59)$ \\
\hline NGO worker & 50 & 40 & $1.55(0.85,2.81)$ & $1.41(0.73,2.72)$ \\
\hline \multicolumn{5}{|l|}{ Resident } \\
\hline Rural & 63 & 96 & 1 & \\
\hline Urban & 133 & 110 & $1.84(1.23,2.77)^{*}$ & $1.49(0.94,2.37)$ \\
\hline \multicolumn{5}{|l|}{ Duration of DM } \\
\hline$\leq 5$ & 147 & 123 & 1 & \\
\hline $6-10$ & 36 & 57 & $0.53(0.33,0.86)^{*}$ & $0.65(0.38,1.13)$ \\
\hline$\geq 10$ & 13 & 26 & $0.42(0.21,0.85)^{*}$ & $0.57(0.26,1.27)$ \\
\hline \multicolumn{5}{|l|}{ Level of income } \\
\hline$<500$ & 80 & 75 & 1 & \\
\hline $500-1500$ & 28 & 40 & $0.67(0.37,1.18)$ & $1.07(0.55,2.08)$ \\
\hline $1501-2500$ & 33 & 53 & $0.59(0.35,1.01)$ & $0.82(0.43,1.55)$ \\
\hline$>2500$ & 55 & 37 & $1.41(0.84,2.38)$ & $1.71(0.89,3.25)$ \\
\hline
\end{tabular}

The present study discloses important information on the level of attitude and practice towards diabetes complications and its associated factors among type 2 DM patients in Ethiopia at Addis Zemen District Hospital. This study showed that over two third (65.2\%) of the study participants had a good attitude level while less than half ( $48.8 \%)$ of study participants had a good practice on DM complications. This finding is supported by a study done in Bangladesh which reported that $66.4 \%$ of participants had a good attitude but regarding practice only $20.1 \%$ were in good practice(20), which is lower than the finding of the present study. The possible justification may be due to socio-economic and cultural differences.

Most (79.9\%) of the respondents reported that they could prevent diabetic complications. This finding is in line with the finding of the same study in Bangladesh where the majority of study participants had reported that they could prevent diabetic complications(20), while in other studies it was only $52.7 \%, 55.6 \%$ and $62.3 \%$ in Ethiopia, India and Pakistan respectively $(22,29,30)$. In this study, good glycemic control was assumed to prevent diabetic complications by only $16.9 \%$ of respondents. On the contrary, the study done in Bangladesh 
showed that majority (66.4\%) of study participant considered good glycemic control as one of the ways to prevent it(20).

This variation could be due to a lack of awareness of type 2 diabetic patients about effect of uncontrolled blood glucose levels. This in turn may be due to lack of counseling by heath professional about the effect of poor glycemic control, as it is the major cause of DM complications, because of their work overload. Only $37.6 \%$ of respondents of the current study monitor their blood glucose level monthly which is lower than the finding of a study done in Bangladesh (95.8\%)(20).

This difference could be due to low awareness of patients on the importance of glycemic control to prevent diabetic complications since only $16.9 \%$ of respondents believe that good glycemic control is important to prevent diabetic complication.

Most (79.9\%) participants of the current study believed that regular exercise prevents further complication is in agreement with a study conducted in Bangladesh (70\%)(20), and less than the study in Indies $97.3 \%(31)$.

However, only $5 \%$ respondents performed exercise on a daily basis which is comparable with the study conducted in Pakistan (8.6\%)(32); but less than the study conducted in Oman (40\%)(31), Indies (40.3\%)(33), Bangladesh (57\%)(20), and west Ethiopia(63.5\%)(23). This low activity in the current study might be due to a lack of habit of exercise or a lack of commitment to do exercise by the study participants. It might also due to inappropriateness of the living environment to do exercise.

Dietary modification was considered as important to prevent diabetic complications by $91.8 \%$. This finding is consistent with the result of a study done in Indies (95.9\%)(31). Regarding practice, $86.6 \%$ of participants practiced dietary modification which is higher than compared to previous studies done in India(31), Oman(33), and west Ethiopia(23), which reported a $49.7 \%, 56 \%$ and $69.5 \%$ of dietary modification practice, respectively. This higher value in Ethiopia as compared to other countries could be due to the content of diet recommended by health professionals is almost similar with what they are practicing regularly. In Ethiopia, the most commonly consumed food is in Amharic 'injera (34). Injera is composed primarily from teff, the smallest grain in the world which is grown primarily in Ethiopia. It is the best choice for helping to control blood glucose(35). More than fifty nine percent of respondents reported about daily feet examination. This finding, is higher than the study done in Nigeria (40.9\%)(36) and Bangladesh(20), where less than $50 \%$ of respondents reported about regular feet examination(20). On the other hand, this finding is lower than the finding of the study done in Saudi Arabia (79.5\%)(21) and Pakistan (94.4\%)(37). This variation could be due to a difference in culture and socioeconomic status.

Only $7.7 \%$ of the current study participants visited an eye specialist. The same finding is reported in Pakistan (10\%)(32). This could be due to lack of awareness about eye complication or due to absence of an eye specialist at the diabetic center, since the research was conducted at district hospital which is known that there is a lack of specialists.

The current study revealed that $29.9 \%$ of the study participants have periodical kidney examination which is lower than the study conducted in Bangladesh (64\%)(20). This may due to lack of a laboratory facility for real examination or lack of awareness about diabetic complications. 
The present study showed that educational status was significantly associated with a good attitude. This finding is supported by other study $(20,38)$ Subjects who can read and write, primary school, and secondary school and above were 2, 4.3 and 2.8 times more likely to have a good attitude than who cannot read and write, respectively. This could be explained by type 2 diabetic patients who are educated has a higher chance of accessing and reading different materials like leaflets, manuals and books and can communicate with health care professionals with no barrier. This in turn helps them to gather information and improve their attitude towards DM complications.

Residence was also found to be significantly associated with a good attitude. Those who were from urban areas had nearly two times a good attitude than those who lived in rural areas. It is consistent with other study(38). This might be due to a difference in an access to information. In urban areas there are different ways of accessing information like television, internet and other technology Medias which are not available in rural areas. In addition, in Ethiopia setup health facilities are mostly located in urban areas, which create a good opportunity for DM patients to have frequent visits and contact with health professionals. This helps patients to have more information about DM complications and to improve their attitude.

Educational status was found to be significantly associated with practice. This is supported by other studies $(18,20,23,30,39)$. Patients who can read and write and high school and above were 2 and 2.6 times more likely to have a good practice for prevention of diabetic complication than those who cannot read and write, respectively. This might be because educated participants are able to read necessary information easily from different written documents; this in turn helps them to improve their level of practice. As the level of education increases, the chance of attending different conferences and seminars on DM also increases. This helps patients to increase their awareness and to improve their practice.

\section{Limitations}

Since the data about attitude and practice of DM complications were self-reported, there may be recall bias and they may respond only socially acceptable responses that may cause an overestimation of some results. Additionally, the study was conducted on all type 2 diabetic patients without considering their diabetic complication history status and complication status during data collection period which affect their attitude and practice level positively or negatively.

\section{Conclusions}

A greater proportion of DM patients has relatively good attitude but poor practice. Educational status was significantly associated with both good attitude and practice, whereas residence was significant contributing factors for only a good attitude. The current study suggests the need of well-organized health educational programs and counseling on complications of diabetes at a regular basis to improve their attitude and practice towards it.

\section{List Of Abbreviations}

DM: Diabetic Mellitus, NGO: Non-governmental Organization, AOR: adjusted odds ratio; Cl: Confidence interval; COR: crude odds ratio; SPSS: Statistical package for social sciences; IDF: International Diabetic Federation

Page 14/18 


\section{Declarations}

\section{Ethics approval and consent to participate}

Ethical approval for the study was obtained from the Institute of Public Health College of Medicine and Health Sciences, University of Gondar. Written informed consent was obtained from all study participants and confidentiality was kept. All the study subjects had answered voluntarily and confidently the administered pretested questionnaires.

\section{Consent for publication}

Not applicable

\section{Availability of data and materials}

The data will be available upon request from the corresponding author upon request.

\section{Competing interests}

None of the authors have any conflicts of interest to declare.

\section{Funding}

Not applicable

\section{Authors' contributions}

YB designs the study, performed data analysis and drafted the manuscript. ${ }^{1} Y A$ involved with designing the study, data analysis, and reviewed the manuscript. ${ }^{2} Y A$ participated with data analysis, designing the study and reviewed the manuscript. All authors read and approved the final manuscript.

\section{Acknowledgements}

We would like to thank the University of Gondar for its support. The data collectors and the study participants are duly acknowledged for kindly given us the information.

\section{Authors' information}

${ }^{1}$ Yitayeh Belsti (BSc, Assistant Lecturer of Medical Physiology): Department of Physiology, College of Medicine and Health Sciences, University of Gondar, Ethiopia

${ }^{2}$ Yonas Akalu (MSc, Lecturer of Medical Physiology): Department of Physiology, College of Medicine and Health Sciences, University of Gondar, Ethiopia.

${ }^{3}$ Yaregal Animut (MPH, Lecturer of Epidemiology and Biostatics, Department of epidemiology and Biostatistics, Institute of Public Health, College of Medicine and Health Sciences, University of Gondar, Gondar, Ethiopia)

\section{References}


1. Classification and diagnosis of diabetes mellitus. Med Clin North Am. 1982;66(6):1191-207.

2. Skolnik R. Noncommunicable Diseases Country Profiles 2018. World Health Organization. 2018.

3. KAISER AB, ZHANG N, DER PLUIJM W VAN. Global Prevalence of Type 2 Diabetes over the Next Ten Years (2018-2028). Diabetes. 2018;67(Supplement 1):202-LB.

4. Cho NH, Shaw JE, Karuranga S, Huang Y, da Rocha Fernandes JD, Ohlrogge AW, et al. IDF Diabetes Atlas: Global estimates of diabetes prevalence for 2017 and projections for 2045. Diabetes Res Clin Pract [Internet]. 2018;138:271-81. Available from: https://doi.org/10.1016/j.diabres.2018.02.023

5. Van Dieren S, Beulens JWJ, Van Der Schouw YT, Grobbee DE, Neal B. The global burden of diabetes and its complications: An emerging pandemic. Eur J Cardiovasc Prev Rehabil. 2010;17(SUPPL. 1).

6. International Diabetes Federation. Eighth edition 2017. IDF Diabetes Atlas, 8th edition. 2017. 1-150 p.

7. Limited seven seas. Global Report on Diabetes. Isbn [Internet]. 2016;5. Available from: http://www.mhra.gov.uk/spc-pil/?prodName=SEVEN SEAS ORIGINAL COD LIVER OIL\&subsName=\&pageID=ThirdLevel\&searchTerm=cod liver oil\#retainDispla

8. Diabetes Uk. Key statistics on diabetes. Diabetes [Internet]. 2010;692(March):1-21. Available from: http://www.diabetes.org.uk/Documents/Reports/Diabetes_in_the_UK_2010.pdf

9. Diabetes UK. Diabetes UK Facts and Figures 2019. Diabetes UK [Internet]. 2019;1-48. Available from: www.diabetes.org.uk

10. Kumar, P. and Clark, M. (n.d.). Kumar \& Clark's clinical medicine. 7th ed..

11. Abebe N, Kebede T, Addise D. Review Article Diabetes in Ethiopia 2000-2016 - prevalence and related acute and chronic complications; a systematic review. 2016;(March 2018):7-12.

12. Zheng Y, Ley SH, Hu FB. Global aetiology and epidemiology of type 2 diabetes mellitus and its complications. Nat Rev Endocrinol [Internet]. 2018;14(2):88-98. Available from: http://dx.doi.org/10.1038/nrendo.2017.151

13. Saunders AF, Brown JT, Mazzuca SA, Vinicor F, Norton JA, Fineberg NS. The diabetes education study. J Gen Intern Med. 1988;3(4):415-6.

14. Schramm TK, Gislason GH, Køber L, Rasmussen S, Rasmussen JN, Abildstrøm SZ, et al. Diabetes patients requiring glucose-lowering therapy and nondiabetics with a prior myocardial infarction carry the same cardiovascular risk: A population study of 3.3 million people. Circulation. 2008;117(15):1945-54.

15. Rhee MK, Slocum W, Ziemer DC, Culler SD, Cook CB, El-Kebbi IM, et al. Patient adherence improves glycemic control. Diabetes Educ. 2005;31(2):240-50.

16. Powers MA, Bardsley J, Cypress M, Duker P, Funnell MM, Fischl AH, et al. Diabetes Self-management Education and Support in Type 2 Diabetes: A Joint Position Statement of the American Diabetes Association, the American Association of Diabetes Educators, and the Academy of Nutrition and Dietetics. Diabetes Educ. 2017;43(1):40-53.

17. Rani PK, Raman R, Subramani S, Perumal G, Kumaramanickavel G, Sharma T. Knowledge of diabetes and diabetic retinopathy among rural populations in India, and the influence of knowledge of diabetic retinopathy on attitude and practice. Rural Remote Health. 2008;8(3):838.

18. Islam FMA, Chakrabarti R, Dirani M, Islam MT, Ormsby G, Wahab M, et al. Knowledge, attitudes and practice of diabetes in rural Bangladesh: The Bangladesh Population based Diabetes and Eye Study 
(BPDES). PLoS One. 2014;9(10).

19. Richard Lewis. Primer Patient counseling. Am J Heal Pharm. 1997;54.

20. Rahaman KS, Majdzadeh R, Naieni KH, Raza O. Knowledge, Attitude and Practices (KAP) regarding chronic complications of diabetes among patients with type 2 diabetes in Dhaka. Int J Endocrinol Metab. 2017;15(3).

21. Al-Hariri MT, Al-Enazi AS, Alshammari DM, Bahamdan AS, AL-Khtani SM, Al-Abdulwahab AA. Descriptive study on the knowledge, attitudes and practices regarding the diabetic foot. J Taibah Univ Med Sci [Internet]. 2017;12(6):492-6. Available from: https://doi.org/10.1016/j.jtumed.2017.02.001

22. Knowledge, attitude and behaviour regarding self-care practices among type 2 diabetes mellitus patients residing in an urban area of South India. UM Int Multidiscip Res J (The Univ Mindanao Res Publ Center). 2013;2(12):31-5.

23. Dedefo MG, Ejeta BM, Wakjira GB, Mekonen GF, Labata BG. Self-care practices regarding diabetes among diabetic patients in West Ethiopia. BMC Res Notes [Internet]. 2019;12(1):1-7. Available from: https://doi.org/10.1186/s13104-019-4258-4

24. Dorosh P, Schmidt E. The Rural-Urban Transformation in Ethiopia. ESSP Work Pap [Internet]. 2010; Available from: http://www.ifpri.org/publication/rural-urban-transformation-ethiopia

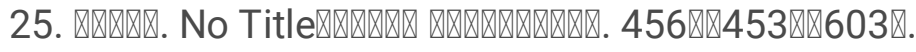

26. Josephine U. Assessment of Knowledge and Attitude towards Diabetes Mellitus among Type 2 Diabetes Patients Attending Biryogo Health Centre. Int J Sci Res Publ. 2018;8(10):577-83.

27. Alsous M, Jalil MA, Odeh M, Kurdi R Al, Alnan M. Public knowledge, attitudes and practices toward diabetes mellitus: A cross-sectional study from Jordan. PLoS One. 2019;14(3):1-12.

28. Gillani AH, Islam FMA, Hayat K, Atif N, Yang C, Chang J, et al. Knowledge, attitudes and practices regarding diabetes in the general population: A cross-sectional study from Pakistan. Int J Environ Res Public Health. 2018;15(9):1-13.

29. Pardhan S, Mahomed I. Knowledge self-help and socioeconomic factors in South Asian and Caucasian diabetic patients. Eye. 2004;18(5):509-13.

30. Feleke SA. Assessment of the Level and Associated Factors with Knowledge and Practice of Diabetes Mellitus among Diabetic Patients Attending at FelegeHiwot Hospital, Northwest Ethiopia. Clin Med Res. 2014;2(6):110.

31. Foster T, Mowatt L, Mullings J. Knowledge, Beliefs and Practices of Patients with Diabetic Retinopathy at the University Hospital of the West Indies, Jamaica. J Community Health. 2016;41(3):584-92.

32. Ahmed MU, Seriwala HM, Danish SH, Khan AM, Hussain M, Husain M, et al. Knowledge, Attitude, and Self Care Practices Amongsts Patients WithType 2 Diabetes in Pakistan. Glob J Health Sci. 2015;8(7):1.

33. Al Bimani ZS, Khan SA, David P. Evaluation of T2DM related knowledge and practices of Omani patients. Saudi Pharm J [Internet]. 2015;23(1):22-7. Available from: http://dx.doi.org/10.1016/j.jsps.2013.12.006

34. Tewahido D, Berhane Y. Self-Care Practices among Diabetes Patients in Addis Ababa: A Qualitative Study. 2017;1-10.

35. Baye K. Teff: nutrient composition and health benefits. 2014;(September). 
36. Desalu O, Salawu F, Jimoh A, Adekoya A, Busari O, Olokoba A. Diabetic foot care: Self reported knowledge and practice among patients attending three tertiary hospital in Nigeria. Ghana Med J [Internet]. 2011;45(2). Available from: http://www.ajol.info/index.php/gmj/article/view/68930

37. Mustafa A, lqbal M, Parvez MA. Assessment of Knowledge, Attitude and Practices of Diabetics Regarding Their Foot Care. Apmc. 2017;11(1):43-7.

38. Fatema K, Hossain S, Natasha K, Chowdhury HA, Akter J, Khan T, et al. Knowledge attitude and practice regarding diabetes mellitus among Nondiabetic and diabetic study participants in Bangladesh. BMC Public Health [Internet]. 2017;17(1):364. Available from:

http://www.ncbi.nlm.nih.gov/pubmed/28446194\%0Ahttp://www.pubmedcentral.nih.gov/articlerender.fcgi? artid=PMC5406895

39. Balagopal P, Kamalamma N, Patel TG, Misra R. A community-based diabetes prevention and management education program in a rural village in India. Diabetes Care. 2008;31(6):1097-104. 